Spring 2015

\title{
An Exploratory Study of Successful Advertising Internships: A Survey Based on Paired Data of Interns and Employers
}

\author{
Pamela K. Morris \\ Loyola University Chicago, pmorris1@luc.edu \\ Seung-Chul Yoo \\ Ewha Women's University
}

Follow this and additional works at: https://ecommons.luc.edu/communication_facpubs

Part of the Communication Commons

\section{Recommended Citation \\ Morris, Pamela K. and Yoo, Seung-Chul. An Exploratory Study of Successful Advertising Internships: A Survey Based on Paired Data of Interns and Employers. Journal of Advertising Education, 19, 1: 5-16, 2015. Retrieved from Loyola eCommons, School of Communication: Faculty Publications and Other Works,}

This Article is brought to you for free and open access by the Faculty Publications and Other Works by Department at Loyola eCommons. It has been accepted for inclusion in School of Communication: Faculty Publications and Other Works by an authorized administrator of Loyola eCommons. For more information, please contact ecommons@luc.edu. c) $($ () $\ominus$

This work is licensed under a Creative Commons Attribution-Noncommercial-No Derivative Works 3.0 License. Author Posting (c) Journal of Advertising Education, 2015. 


\title{
An Exploratory Study of Successful Advertising Internships: A Survey Based on Paired Data of Interns and Employers
}

\author{
Seung-Chul Yoo, Ewha Womans University \\ Pamela Morris, Loyola University Chicago
}

\begin{abstract}
As the job market becomes increasingly competitive, advertising educators must help students develop stronger skills, prepare for career positions and become more attractive to employers. Internships are a way for students to acquire critical real-world proficiencies and stand out in a job search. At the same time, employers benefit from and rely on internship programs, from learning new communication platforms to filling full-time positions. Using data from a field survey, this study provides a new understanding of the key elements and proposes a model for successful advertising internship programs. The investigation is unique, as the analysis pairs data from both interns and their employers. Findings show that a student's major and supervisor support contribute to overall satisfaction with the internship, leading to higher employer motivation ratings that correlate with higher work performance evaluations and intention to hire scores. Practical implications for advertising internship managers and future research directions are discussed.
\end{abstract}

\section{Introduction}

Widely recognized as an important part of students' education, as well as a valuable resource for employers, college internship programs are flourishing (Gault, Redington \& Schlager, 2000). Most colleges and universities have some type of internship curriculum (Roznowski \& Wrigley, 2003). Becker, Vlad and Kalpen (2011) reported that $81 \%$ of communication students who graduated in 2011 had completed an internship during their college years. For advertising students in particular, a 2008 nationwide online survey revealed that $53 \%$ of students had held at least one internship during their college careers (Kendrick, Fullerton \& Rodak, 2010).

Internships provide supervised practical experience and exposure to real-world problems and issues not covered in classroom lectures or textbooks. Through a combination of work and learning, interns gain firsthand knowledge relevant to their major, start to realize individual skills, model professional behaviors, build resumes, clarify career-goals and prepare for future employment. The aim of internships is to create a natural bridge between college and industry (Coco, 2000). Building a relationship among educators and businesses is nothing new and one of the first recorded efforts was in 1906 at the University of Cincinnati's Cooperative Education Program (Thiel \& Hartley, 1997).

Sweitzer and King (2009) refer to internships as "learning experiences that involve receiving academic credit for learning at an approved site, under supervision" (p. 3). Internships combine learning and work, and the expectation is that through internships, students will gain firsthand knowledge relevant to their majors and build their resumes -- important attributes for securing professional employment after graduation. Roznowski and Wrigley (2003) described the purpose of internships as the opportunity for students to gain an understanding of the daily practices within a professional working environment and to develop industry specific proficiencies. Typical internship programs can be characterized with four or five attributes: 1) a specified number of work hours; 2) paid or unpaid employment; 3 ) credit for college courses; and 4) supervision by a faculty coordinator or other university contact (Gault et al., 2000; Roznowski \& Wrigley, 2003). In addition, Narayanan, Olk and Fukami (2010) suggested a fifth key descriptor - supervision by a company or organization mentor.

Internship programs are made up of complex relationships involving educators, students 
and employers. The wide variation of these stakeholder groups requires that organizations carefully plan and professionally manage internship programs in order to achieve educational objectives (Gault et al., 2000). Coco (2000) outlined several suggestions for how host companies and organizations can maximize the effectiveness of internship programs, such as providing instruction, involving interns in the project preparation process, assigning accomplishable goals, rotating interns throughout the organization and explaining to interns the rationale behind work tasks. The author suggested that employers manage interns professionally and as part of the organizational staff, holding them accountable for projects and deadlines. These considerations suggest that appointing an intern mentor or supervisor is crucial.

Surprisingly, there are few empirical studies about how employers can ensure that internship programs achieve success. The majority of the literature on internship experiences is largely descriptive, lacks theoretical perspectives and is deficient in hypotheses testing (Narayanan et al., 2010). Thus, in the context of advertising education, the goal of this research is to provide an empirical foundation and suggestions on how to improve internships by providing a model linking internship satisfaction with employer evaluation and intention-to-hire data. Having the three actors of college internship programs (i.e., college, student and employer) in one theoretical model is essential to better understand what contributes to internship success. The paper begins with a review of the extant literature and presents a conceptual model for successful internships. The next sections provide the methods employed for model testing, findings and discussion for the academic and practical implications of the study.

\section{Literature Review \\ Benefits of College Internships}

Previous articles have outlined the benefits of internship programs particularly for students and host employers. Here we highlight some of the advantages.

Students. Students gain valuable experience by working in professional environments alongside practitioners to see firsthand how classroom concepts relate to real-world practical applications (McDonough, Rodriquez \& Prior-Miller, 2009). Internships provide students the opportunity to learn more about an industry, possible career paths, personal interests and professional ambitions (Coco, 2000). In a survey of 227 undergraduate and graduate marketing students, Karns (2005) found that internships ranked at the top in terms of pref- erence and learning effectiveness, and above other pedagogical activities, such as class discussions and case analyses. While students reported internships as challenging, demanding and requiring much effort, internships were also perceived to be the most stimulating, applied, active and, overall, an enjoyable learning tool.

Previous studies have found that internship experience helps students become better prepared to enter the job market and provides students a competitive advantage, from attaining their first entry-level professional positions to advancing in their early careers (Gault et al., 2000). For advertising students specifically, a nationwide online survey found that seniors who had held internships were significantly more likely to receive a job offer, compared to students not holding internships, although, contrary to the previous studies mentioned, the authors here reported no differences for starting salary between the two groups (Kendrick et al., 2010).

Other investigations have attempted to discover intrinsic outcomes rewarded to students due to internship work. Gault et al. (2000) provided empirical evidence to reveal that interns report greater overall job satisfaction. Toncar and Cudmore (2000) content analyzed student journals and reflective essays, and interviewed students to identify benefits of an overseas internship program. The primary themes gleaned from the data were that students were influenced by and had changed because of the experience. While based on an international field experience, these outcomes are also found in general internship experiences (Sweitzer \& King, 2009).

Employers. Companies and organizations hosting internships have much to gain. Interns provide work-related knowledge and tangible skills (Gault et al., 2000), and fertile ideas can be expanded among supervisors to help businesses stay current and grow (Thiel \& Hartley, 1997). Specific to advertising, interns can contribute by using new expertise acquired from classes, such as non-conventional messaging, digital platforms and interactive strategies. In this way, employers learn from interns. Interns also can provide positive public relations for the host organizations (Toncar \& Cudmore, 2000). Moreover, interns can cover routine tasks, allowing full time employees to tackle more demanding projects (Roznowski \& Wrigley, 2003).

Internship programs also create a recruitment channel for employers to preview prospective employees for their work ethic, attitude, technical competence and organiza- 
tional fit (Toncar \& Cudmore, 2000). These efforts may also help in employee retention. According to the National Association of Colleges and Employers Internship \& Coop Survey Report (2013), retention rates a year after hire for employees who came from employers' internship or co-op programs averaged $89 \%$, compared to $80 \%$ for those who did not complete an internship with the organization.

While these studies are important, they are descriptive and provide little insight into how organizations can create and manage effective internship programs. The next section summarizes investigations that have explored preconditions and outcomes of successful internships and proposes hypotheses for study.

\section{Student Satisfaction and Employer Percep- tions}

The concept of job satisfaction can be described as "an overall affective orientation on the part of individuals toward work roles which they are presently occupying" (Kalleberg, 1977, p. 126), or as an employee's affective reactions to a job based on comparing desired outcomes with actual outcomes (Cranny, Smith \& Stone, 1992). The ongoing challenge for internship programs is to maximize a student's positive internship experience, which will simultaneously meet intended learning outcomes through the most effective internship program design.

Beebe, Blaylock and Sweetser (2009) explored the relationship between pay and internship satisfaction, determined by Job Descriptive Index (JDI) and Job in General (JIG) index scales, among students in the communication college at a large university. Their study revealed that while paid interns were more satisfied with their work experience than unpaid interns, unpaid interns were not dissatisfied. More importantly, students ranked three specific qualities -- learning job skills, having a good supervisor and gaining the opportunity for career advancement -- higher than salary and more predictive of internship satisfaction.

\section{Relevancy between major and internship duties}

Other studies have found consistency for factors students perceive as rewarding about their internships with those that employees identify as satisfying in permanent positions based on the job characteristics model (Narayanan et al., 2010), which is composed of skill and task variety, task significance, autonomy and job feedback (Spector, 1997). In addition, the knowledge transfer theory, suggesting that success is affected by an individual's prepa- ration for a new role, is frequently used in personnel and organizational procedures and can be applied to investigations of internship programs. The theory can be explained as a process with three components: antecedents or inputs, processes and outcomes (Narayanan et al., 2010).

In this way, internship readiness, such as prior coursework and involvement in becoming aware of and selecting the internship, can help prepare an individual for the actual learning experiences at the internship and is likely to lead to more positive internship outcomes (Narayanan et al., 2010).

\section{Hypotheses}

For the present study, we suggest that when academic majors and internship duties are more congruent, students will achieve greater satisfaction with their internships. Constructed from this assumption is the first hypothesis.

H1: Perceived major-internship job relevancy is positively correlated with internship satisfaction.

Internship supervisor support. Supervision is an important aspect of a successful internship. For instance, Beard and Morton (1999) investigated attributes of advertising and public relations interns and found that the quality of employer supervision was the most important characteristic for successful internship experiences, measured in student evaluation of having gained interpersonal and technical skills, practical experience and career focus. In another study, McDonough et al. (2009) surveyed both students and supervisors for job performance at mid-semester and at the end of the term. On a series of questions exploring general aptitudes and workplace proficiencies, specific job skills, interpersonal communication abilities and basic professional conduct, students rated their performances higher than did the students' supervisors. However, the responses became more congruent through the semester. The authors attributed the change to more communication and interactions between interns and their supervisors, which reflected that learning was taking place as interns began to comprehend requirements of the position and were better able to evaluate their own performance.

Other studies have shown (e.g., Beebe et al., 2009) that having a good supervisor at a workplace ranked highest or among the highest in predicting internship satisfaction. In addition, Narayanan et al. (2010) suggested that the more involved the organization mentor was in providing supervisory support and feedback to the student during the internship, the better the in- 
ternship outcome. This assumption leads to the next hypothesis.

H2: Perceived supervisor support is positively correlated with internship satisfaction.

The next group of hypotheses is based on the interconnectedness of intern satisfaction with employer ratings of motivation, performance and intention to hire.

Motivation. Satisfaction is implicated in motivation and, as an antecedent of job satisfaction, motivation has three capacities in behavior: directing, sustaining and energizing (Cranny et al., 1992). The five core attributes of the job characteristics theory described earlier also contribute to motivation (Spector, 1997). Spector summarizes the relationship: "people who prefer challenge and interest in their work will be happier and more motivated if they have complex jobs, as defined by the five core characteristics" (p. 33-34). In the study described previously, Karns (2005) revealed this dynamic specific to internships, that is, even though considered challenging, demanding and requiring more effort, students perceived internships as enjoyable.

Researchers have applied the job characteristics model to student internship programs to suggest that when the position provides challenging work, offers autonomy and creates an opportunity for learning, the more motivated the intern should be and, eventually, the more satisfied with the internship (Narayanan et al., 2010). These qualities should likely lead to more posi- tive supervisor evaluations. The next hypothesis focuses on motivation.

H3: Intern satisfaction is positively correlated with employer rating of intern motivation.

Performance. As already mentioned, motivation is an important factor in directing behavior and job satisfaction (Cranny et al., 1992). Pinder (2008) defines work motivation as "a set of energetic forces that originate both within as well as beyond an individual's being, to initiate work-related behavior, and to determine its form, direction, intensity, and durations" (p. 11). A high level of work motivation leads to active participation, commitment, identification with and willingness to extend effort (Narayanan et al., 2010). Such efforts should yield better performance. The next hypothesis reviews this relationship.

H4: Employer rating of intern motivation is positively correlated with employer rating of intern work performance.

Hiring intention. The higher the employer rating of their intern for motivation and performance, the more likely the employer should want to hire the intern. We base the last two hypotheses on this proposition.

H5: Employer rating of intern motivation is positively correlated with intention to hire.

H6: Employer rating of intern work performance is positively correlated with intention to hire.

\section{Proposed Model}

The present study focuses on the overall re-

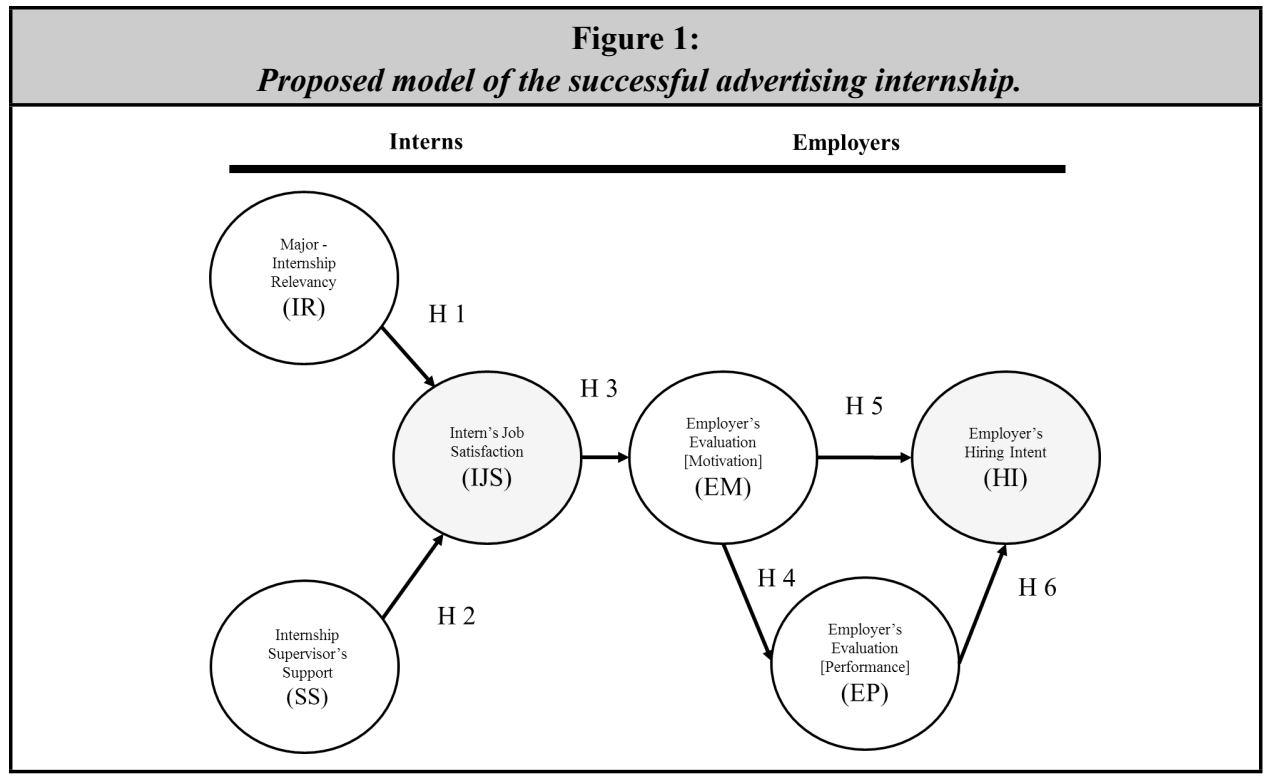


lationships of factors related to advertising internships to further the understanding of the multiple paths that connect students' satisfaction with internships and employers' perceptions of interns. We created a conceptual model whose variables are ordered based on previously demonstrated relationships, as cited in the literature reviewed.

In the block recursive model, the first set of variables include major/internship relevancy and supervisor support. The two exogenous variables are expected to have direct effects on student satisfaction. In turn, it was hypothesized that student satisfaction would directly connect to the degree of employer evaluation toward the intern in terms of motivation. Here, intern motivation and performance ratings also are expected to have positive impacts on employer hiring intention. Further, it was anticipated that interns' motivation affects their work performance evaluation. Perceived level of intern performance is expected to mediate the relationship between perceived level of intern motivation and employer hiring intention. The proposed model appears in Figure 1.

\section{Method}

\section{Participants and Procedures}

Data were collected from the advertising internship program at a large Southwestern university. The director of the program identified a list of students participating in internships and supervised the data collection used in the present study. A total of 299 students enrolled in advertising internship courses for credit were surveyed at the end of the term using a Web-based questionnaire $\left(\mathrm{N}_{0}\right.$ $=299$ ). An initial solicitation email and two reminder emails yielded 254 completed questionnaires $\left(\mathrm{N}_{\mathrm{I}}=254,85 \%\right.$ return rate $)$. Of the participants, $75 \%$ were female, $99 \%$ between the ages of 18 and $25(\mathrm{M}=21.98, \mathrm{SD}=0.14)$ and $85 \%$ native English speakers. The majority $(64 \%)$ were Caucasian, while $17 \%$ were Latino, 12\% Asian, 4\% African American and the rest marked "other" as their racial heritage. The group consisted of 206 seniors (82\%), 26 juniors $(10 \%)$ and 20 master's students $(8 \%)$. The demographic profile of the participants is presented in Table 1. In addition, Table 2

Table 1:

Intern Demographic Profile $(N=254)$

\begin{tabular}{|lrc|}
\hline & $n$ & Percentage $(100 \%)$ \\
\hline Gender & 61 & 24.0 \\
Male & 190 & 74.8 \\
Female & & \\
Race & 162 & 63.8 \\
Caucasian & 44 & 17.3 \\
Latino & 31 & 12.2 \\
Asian & 11 & 4.3 \\
African American & 5 & 2.0 \\
Other & & \\
School Year & 26 & 10.2 \\
Junior & 206 & 82.1 \\
Senior & 20 & 7.9 \\
Master's student & & \\
Previous internship experience & 103 & 4.9 \\
No (0) & 60 & 6.7 \\
Once (1) & 50 & 23.6 \\
Twice (2) & 20 & 19.7 \\
Three times (3) & 17 & 70.6 \\
More times or more & & \\
\hline
\end{tabular}




\begin{tabular}{|lcc|}
\hline \multicolumn{3}{|c|}{$\begin{array}{c}\text { Table 2: } \\
\text { Internship Characteristics }(\boldsymbol{N}=\mathbf{2 5 4})\end{array}$} \\
\hline & $n$ & Percentage (100\%) \\
\hline Public Relations (PR) / Media Relations & 80 & 31.5 \\
Advertising Account Service & 36 & 14.2 \\
Advertising Media (Media Planning/Buying) & 29 & 11.4 \\
Event Planning & 20 & 7.9 \\
Consumer Research & 17 & 6.7 \\
Creative (Advertising Copywriting and Design) & 17 & 6.7 \\
Sales Promotion & 12 & 4.7 \\
Interactive / Digital Advertising & 9 & 3.5 \\
General Advertising Management & 6 & 2.1 \\
Other Advertising Jobs & 28 & 11.0 \\
\hline
\end{tabular}

shows how most of the participants interned at advertising agencies or client-side advertising related departments.

Evaluations from employers also were collected at the end of the semester $\left(\mathrm{N}_{\mathrm{E}}=299\right)$. To receive credit for the internship, worksite supervisors were required to provide evaluations of their interns to the internship coordinator. Supervisor assessments were collected via various methods including mail, fax, email and in person $\left(\mathrm{N}_{\mathrm{E}}=299,100 \%\right.$ return rate). Specifically, supervisors were asked to rate their interns in terms of motivation and performance during their employment. In addition, hiring intentions toward interns were also assessed. Later, the students' responses and their supervisors' evaluations were paired $\left(\mathrm{N}_{\mathrm{P}}=254\right.$ pairs) at an individual level (i.e., intern \#1 - supervisor \#1) and analyzed.

\section{Measures}

The following summarizes how each concept was operationalized and considered previous literature, while specific survey questions used for each item are offered in Table 3.

Major/internship relevancy. Major/internship relevancy (IR) was measured by asking students to rate the relevancy of their internship to their major based on a sevenpoint semantic differential scale (not relevant to the major - highly relevant to the major).

Supervisor support. Supervisor support (SS) was measured using the scales developed by Karasek and Theorell (1990). Consisting of four statements, students could respond using a seven-point Likert-type scale (strongly agree - strongly disagree). To form a supervisor support index score, responses were averaged and the internal consistency for the index is $\alpha_{S S}=.90$.

Internship job satisfaction. This study had an internship job satisfaction (IJS) question using a single item (Quinn \& Staines, 1979). Students were asked to indicate their level of overall satisfaction with their internship on a seven-point Likert-type scale (not satisfied highly satisfied).

Employer perceptions. We assessed employer evaluations of their interns' work motivation and performance. Work motivation (EM) was directly measured by asking "Please rate your intern's work motivation compared to other interns you currently supervise or have recently supervised." Similarly, work performance (EP) was measured by asking "Please rate your intern's work performance compared to other interns you currently supervise or have recently supervised." Both measures applied a single-item, five-point Likert-type scale ranging from 1 (Poor) to 5 (Superior).

Hiring intentions. In the present study, the measurement tool for assessing employer hiring intention (HI) was based on the principles of the Theory of Planned Behavior (TPB) (Ajzen, 1991), which has been widely used in predictions of hiring decisions and behaviors (e.g., Fraser et al., 2010). Hiring intention was assessed with three questions (e.g., "How likely are you to plan to hire your intern student if you have an opening next year?"). Responses used a seven-point Likert-type scale (extremely unlikely - extremely likely). Employer scores were averaged to create a hiring intention index for the ensuing analysis. This scale was proven to be reliable $\left(\alpha_{\mathrm{HI}}\right.$ $=.97$ ). 


\section{Results}

\section{Descriptive Statistics}

The 254 students participating in the survey reported strong major/internship relevancy $\left(\mathrm{M}_{\mathrm{IR}}=5.87, \mathrm{SD}_{\mathrm{IR}}=1.34\right)$. Overall, interns have positive perceptions toward their internships as shown in Table 4. Along with IR, the mean value of SS and IJS exceeded five out of seven $\left(\mathrm{M}_{\mathrm{SS}}=5.90, \mathrm{SD}_{\mathrm{SS}}=1.12\right.$ and $\mathrm{M}_{\mathrm{IJS}}$ $=5.88, \mathrm{SD}_{\mathrm{IJS}}=1.14$, respectively). The employers also evaluated their interns positively. Employers perceived interns as highly motivated $\left(\mathrm{M}_{\mathrm{EM}}=4.61, \mathrm{SD}_{\mathrm{EM}}=.64\right)$ and rated their work performance as effective $\left(\mathrm{M}_{\mathrm{EP}}=\right.$

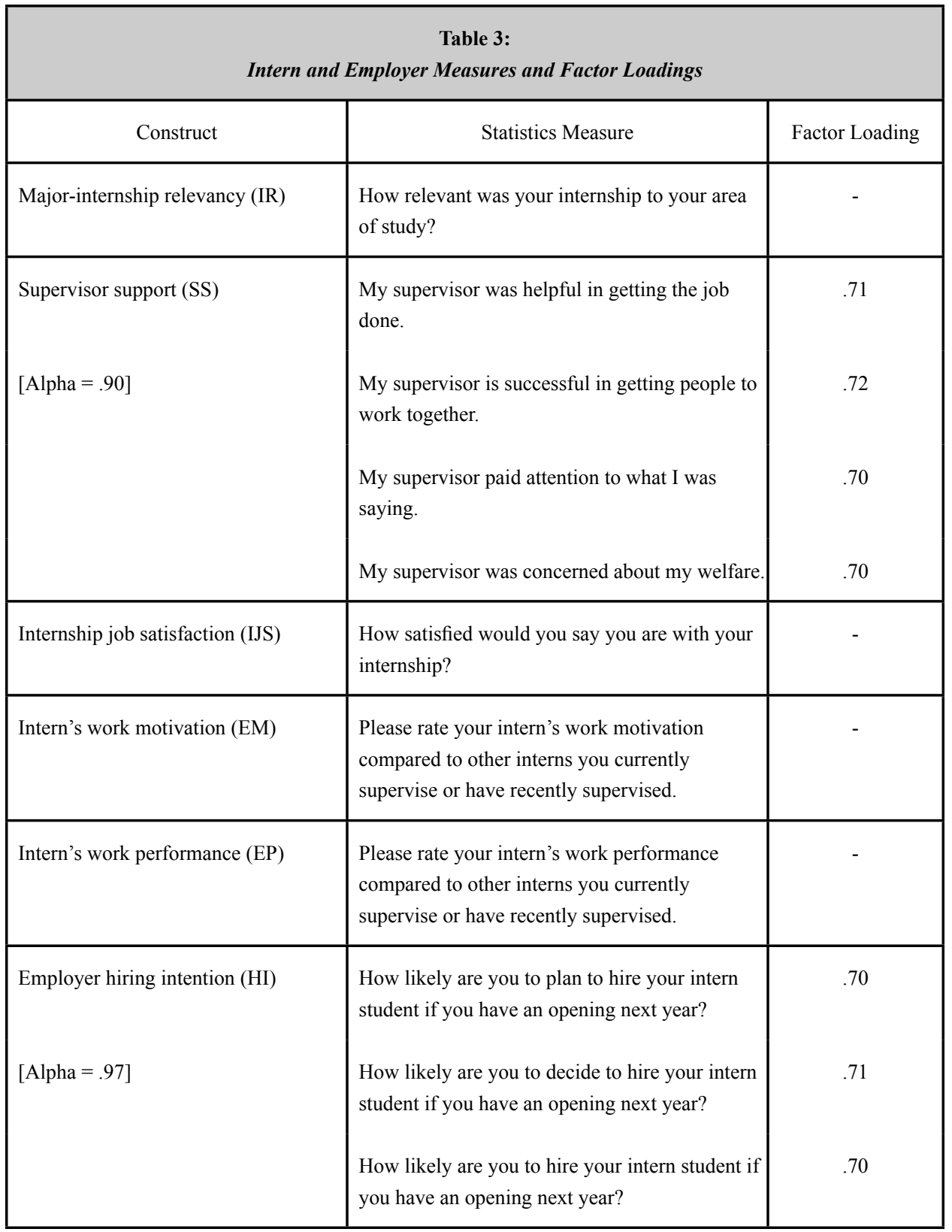

Note. All factor loadings are significant: $p<.01$. 
4.45, $\mathrm{SD}_{\mathrm{EP}}=.66$ ) (both based on a five-point scale). Employers also indicated that they would likely hire interns in the future if there are openings $\left(\mathrm{M}_{\mathrm{HI}}=5.83, \mathrm{SD}_{\mathrm{HI}}=1.19\right.$, based on a seven-point scale).

\section{Data Analysis}

We assessed the hypotheses using structural equation modeling (SEM). The analysis is considered appropriate to understand direct, indirect and moderated relationships in our conceptual model (Anderson \& Gerbing, 1988), and AMOS 18 program was utilized. In particular, we tested the measurement model before testing the proposed model following the two-step approach (Hair, Black, Babin \& Anderson, 2010). A data set of 254 internsupervisor pairs was applied for the analysis. As can be seen from Table 3, the measurement model showed that all the composite reliability values are higher than 0.90 and the average variances are at or above 0.70 . Correlations, means and standard deviations used in this study are presented in Table 4 . The structural model was estimated using the maximum likelihood method (MLE) and the significance of all paths among the latent variables was tested at the 95 percent confidence level. The overall fit of the proposed model is above the recommended criteria (Schermelleh-Engel, Moosbrugger \& Müller, 2003) suggesting a good model fit: $\chi 2 / \mathrm{df}=2.151$, GFI $=0.921$, AGFI $=0.900$, CFI $=0.981$, NFI $=0.932$, $\mathrm{RMSEA}=0.042$.

\section{Tests of the Model}

The first step in testing the fit of the model (Figure 1) was to estimate the paths. Figure 2 presents the results of the structural model with standardized path coefficients between constructs identified by lines. The estimate of the standardized path coefficient indicates that the connection between IR and IJS (H1) is highly significant $(\beta=.39, p<.001)$. The relationship between SS and IJS (H2) is also significant $(\beta=.37, p<.001)$. Together, the two paths accounted for approximately $76 \%$ of the observed variance in IJS. In addition, IJS has a significant and direct impact on EM (H3) $(\beta=.13, p<.05)$. Support also was demonstrated for Hypothesis 4 , as the effect of EM on EP was quite strong $(\beta=.64, p<.001)$. Finally, both EM and EP have a significant and direct impact on HI, supporting Hypothesis 5 $(\beta=.29, p<.01)$ and Hypothesis $6(\beta=.75$, $p<.00)$ respectively. Structural coefficients of the model are detailed in Figure 2 and Table 5.

\section{Discussion}

Over the past several years, the use of internships as part of professional training has increased (Gault et al., 2000). The present research suggested and tested a conceptual model for effective advertising internships. The results of our analyses were consistent with the hypotheses. Through the series of tests, this study developed comprehensive understanding of how student major-internship relevancy and internship supervisor support influence job satisfaction. In turn, high satisfaction leads to positive employer evaluations and considerations for future employment.

One of the primary objectives of internship learning is to increase the chances for landing a "real" job after graduation. The data from our employer surveys revealed that an intern's job satisfaction record leads to employers' positive evaluation of interns, in terms of work motivation and hiring intention. While an intern's job satisfaction estimation does not foretell an employer's positive performance evaluation directly, an intern's job satisfaction score does have meaningful indirect impact on performance assessment via work motivation evaluation in the model. Not surprisingly, higher motivation scores are connected to bet-

\begin{tabular}{|c|c|c|c|c|c|c|c|c|}
\hline \multicolumn{9}{|c|}{$\begin{array}{c}\text { Table 4: } \\
\text { Intern and Employer Measures } \\
\text { Means, Standard Deviations and Bivariate Correlations }\end{array}$} \\
\hline Measure & M & SD & 1 & 2 & 3 & 4 & 5 & 6 \\
\hline 1. Major/ internship relevancy (IR) & 5.87 & 1.34 & 1 & - & - & - & - & - \\
\hline 2. Supervisor support (SS) & 5.90 & 1.12 & $.35 * *$ & 1 & - & - & - & - \\
\hline 3. Internship job satisfaction (IJS) & 5.88 & 1.14 & $.59^{* *}$ & $.53 * *$ & 1 & - & - & - \\
\hline 4. Internship work motivation (EM) & 4.61 & .64 & .09 & $.21 * *$ & $.23^{* *}$ & 1 & - & - \\
\hline 5. Internship work performance (EP) & 4.45 & .66 & .02 & $.19^{* *}$ & $.14 *$ & $.65 * *$ & 1 & - \\
\hline 6. Employer hiring intention $(\mathrm{HI})$ & 5.83 & 1.19 & .11 & .10 & $.18^{* *}$ & $.43 * *$ & $.52 * *$ & 1 \\
\hline
\end{tabular}

Notes. ${ }^{*} p<.05 .{ }^{*} p<<.01$. 
Figure 2:

Direct effects with statistically significant beta coefficients.

Interns

Employers

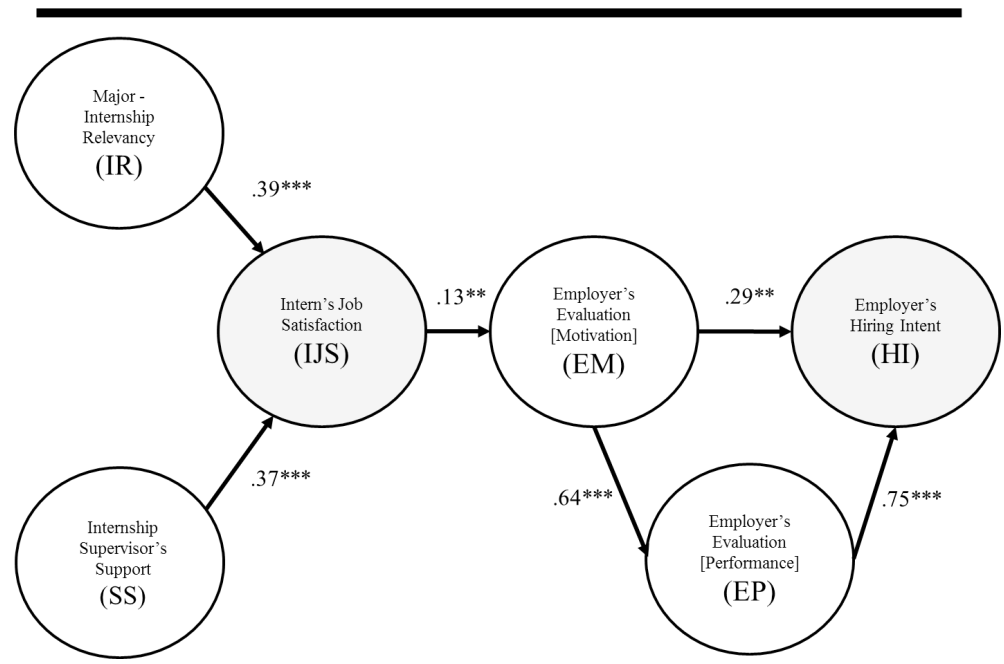

Notes. Solid lines represent hypothesized significant direct effects; ${ }^{*} p<0.05 ; * * p<0.01 ; * * * p<0.001$.

\section{Table 5:}

Standardized Path Coefficients in the Final Model

\begin{tabular}{|c|lrl|c|c|}
\hline \multicolumn{3}{|c|}{ Structural path } & $\begin{array}{c}\text { Stand. } \\
\text { estimate }\end{array}$ & p-value \\
\hline H1 & Major-internship job relevancy & $\rightarrow$ & Internship satisfaction & .39 & .000 \\
\hline H2 & Internship supervisor support & $\rightarrow$ & Internship satisfaction & .37 & .000 \\
\hline H3 & Internship satisfaction & $\rightarrow$ & Intern's work motivation & .13 & .009 \\
\hline H4 & Intern's work motivation & $\rightarrow$ & Intern's work performance & .64 & .000 \\
\hline H5 & Intern's work motivation & $\rightarrow$ & Employer's intention to hire & .29 & .001 \\
\hline H6 & Intern's work performance & $\rightarrow$ & Employer's intention to hire & .75 & .000 \\
\hline
\end{tabular}

Notes (Goodness of fit indices):

Final Model: $\chi 2 / \mathrm{df}=2.151, \mathrm{GFI}=0.921, \mathrm{AGFI}=0.900, \mathrm{CFI}=0.981, \mathrm{NFI}=0.932, \mathrm{RMSEA}=0.042$.

ter work performance appraisals.

Our results have important implications for managing internship programs. First, the findings indicate that major/internship relevancy is very important in terms of how satisfied an intern is with his or her job. Therefore, to foster a higher level of intern job satisfaction, college internship directors need to provide suitable and holistic counseling. This includes exploring the wide and diverse professions in the advertising industry with students. Be- cause the business is dynamic and complex, this requires educators to have current and thorough or insider understanding of the industry. Educators need to know the hidden and exciting career opportunities beyond creative, media and account management, and should consider editing, production, digital, research and other tasks that work to create integrated advertising and communication campaigns.

Program directors should also thoughtfully guide advertising majors by considering the 
context and understanding of students' cultural background, educational experience and practical skill set. A pre-semester analysis and reflection is one suggestion that may help students ground their current situation, interests and goals. The effort could encourage discoveries that lead to the most appropriate internship position. Especially in today's marketplace, students can take advantage of their multicultural skills, passionate hobbies and technological savvy by finding opportunities at boutiques, specialty communication organizations and emerging niche agencies that specialize in target audience, strategy, production or other areas of the business.

In addition, the results of the present study suggest that direct supervision at the worksite also has sway on intern job satisfaction. The implication is that supervisors should consider their interns as important individuals worthy of respect and dignity and attempt to recognize each individual's unique needs and motivations. This is also an opportunity for practitioners to model professional, moral and ethical behaviors. Social Learning Theory suggests that students will learn more than advertising proficiencies at an internship and it is the intrinsic skills that are just as important to a healthy industry (Hanna, Crittenden \& Crittenden, 2013). Creating a friendly and supportive workplace atmosphere is crucial for enhancing intern job satisfaction.

There is more to directing interns than just placing interns at internship jobs. Collegelevel internship directors can improve student satisfaction of their internships and have a responsibility to ensure that each student has an appropriate position and fitting supervisor or mentor at their workplace to help create a bridge into a professional career.

Failure to achieve internship job satisfaction will likely affect not only employer perceptions of intern work performance but, through work motivation, it will also influence employers' hiring intention. Thus, student internship job satisfaction is beneficial for interns as well as for employers. Considering that intern job satisfaction seems to take an important role in intern work motivations, performances and employers' future hiring decisions, the model presented in the current work provides resourceful guidance to internship directors at university-level advertising programs.

\section{Limitations and Future Research}

Although the findings of this study confirmed our hypotheses and have significant implications in advertising internship management, we would like to acknowledge a few methodological limitations. The key drawback of the present investigation is the narrow sampling of subjects. That is, the data should be interpreted with caution, as the study was based on a convenience sample collected from one university. While we recruited a relatively large number of interns and their employers, particular aspects of our sampling area, such as cultural and socioeconomic characteristics, must be taken into account. Future research could use the findings from this study and explore participants from internship programs of several universities in different geographical locations.

The concept of hiring intent could also be skewed, as some students may not seek to continue in the job market after graduation. Instead, they may be considering taking time off, traveling, enrolling in graduate school, pursuing a career in another field or already have a job offer with some other organization. In these cases, the employer may not even think about extending a job offer to the intern. Such alternatives should be thought about in review of the analysis.

Furthermore, a number of variables in the present study were quantified by single-item measures due to the nature of this field inquiry (e.g., limited time and resources, difficulties in logistics of running a lengthy survey). Since the present work was mainly interested in gaining an overall understanding about the constructs in a college advertising internship, a single-item measure is still acceptable for that purpose (Lee, Delene, Bunda \& Kim, 2000,). In particular, although single item scales are usually criticized, the correlation between the multiple item job satisfaction scale and the single item job satisfaction scale has been known to be highly reliable (Parry \& Warr, 1990; Wanous, Reichers \& Hudy, 1997). Further, Wanous et al.'s (1997) meta-analysis of the literature confirmed that the minimum estimated test-retest reliability for single item scales was also high. Future research could examine key variables involved in internships by applying full-length multipleitem scales.

Other suggested investigations include fielding a longitudinal study that accesses intern job satisfaction and employer work motivation and performance evaluations and a comparative study exploring differences and similarities of intern outcomes by occupation category. In addition, future inquiries could add observational and qualitative approaches such as focus group interviews and journal analyses in order to obtain deeper understanding about interns and their employers. We also encourage future researchers to investigate the full nature of advertising intern- 
ships by employing other theoretical ideas, such as a social learning paradigm. For example, our model can be extended by adding self-efficacy and outcome expectation concepts, as these may affect job satisfaction. It would also be worthwhile to include other factors, such as interns' academic performance (i.e., GPA scores). Such investigations would provide a more thorough understanding of internship success.

\section{Conclusion}

The findings from our conceptual model provide recommendations for advertising internship directors in colleges and some insights into internship management for employers. It is essential that directors of advertising internship programs understand the importance of an intern's satisfaction with his or her job, be cautious about recommending companies and organizations appropriate for each student's major and choose individual employers who can provide supportive supervision. By sending qualified students into various advertising functions, internship programs can help students explore career alternatives, gain practical skills and define career goals under the supervision of industry professionals. Such insights are important for the development of effective advertising internship programs as well as the future of the advertising industry.

\section{References}

Ajzen, I. (1991). The theory of planned behavior. Organizational Behavior and Human Decision Processes, 50(2), 179-211.

Anderson, J. C., \& Gerbing, D. W. (1988). Structural equation modeling in practice: A review and recommended two-step approach. Psychological Bulletin, 103(3), 411-23.

Beard, F., \& Morton, L. (1999). Effects of internship predictors on successful field experience. Journalism and Mass Communication Educator, 53(4), 42-53.

Becker, L. B., Vlad, T., \& Kalpen, K. (2011). 2011 Annual survey of journalism \& mass communication graduates. Grady College of Journalism \& Mass Communication. Retrieved February 17, 2015, from http://www.grady.uga.edu/annualsurveys/ Graduate Survey/Graduate_2011/Grad2011COMBINEDbw.pdf

Beebe, A., Blaylock, A., \& Sweetser, K. D. (2009). Job satisfaction in public relations internships. Public Relations Review, 35(2), 156-58.

Coco, M. (2000). Internships: A try before you buy arrangement. SAM Advanced Management Journal, 65(2), 41-43, 47.

Cranny, C. J., Smith, P. C., \& Stone, E. F. (1992). Job satisfaction: How people feel about their jobs and how it affects their performance. New York: Lexington Books.

Fraser, R. T., Johnson, K., Hebert, J., Ajzen, I., Copeland, J., Brown, P., \& Chan, F. (2010). Understanding employers' hiring intentions in relation to qualified workers with disabilities: Preliminary findings. Journal of Occupational Rehabilitation, 20(4), 42026.

Gault, J., Redington, J., \& Schlager, T. (2000). Undergraduate business internships and career success: Are they related? Journal of Marketing Education, 22(1), 45-53.

Hair, J. F., Black, W. C., Babin, B. J., \& Anderson, R. E. (2010). Multivariate data analysis: A global perspective (7th ed.). Upper Saddle River, NJ: Pearson Education.

Hanna, R. C., Crittenden, V. L., \& Crittenden, W. F. (2013). Social learning theory: A multicultural study of influences on ethical behavior. Journal of Marketing Education, 35(1), 18-25.

Kalleberg, A. L. (1977). Work values and job rewards: A theory of job satisfaction. American Sociological Review, 124-43.

Karasek, R. A., \& Theorell, T. (1990). Healthy work: Stress, productivity, and the reconstruction of working life. New York: Basic Books.

Karns, G. L. (2005). An update of marketing student perceptions of learning activities: Structure, preferences, and effectiveness. Journal of Marketing Education, 27(2), 163-71.

Kendrick, A., Fullerton, J., \& Rodak, M. (2010). Advertising student interns: Career preferences and ethical issues. Journal of Advertising Education, 14(2), 42-51.

Lee, H., Delene, L. M., Bunda, M. A., \& Kim, C. (2000). Methods of measuring healthcare service quality. Journal of Business Research, 48(3), 233-46.

McDonough, K., Rodriguez, L., \& Prior-Miller, M. R. (2009). A comparison of student interns and supervisors regarding internship performance ratings. Journalism \& Mass Communication Educator, 64(2), 140-55.

Narayanan, V. K., Olk, P. M., \& Fukami, C. V. (2010). Determinants of internship effectiveness: An exploratory model. Academy of Management Learning \& Education, 9(1), 61-80.

National Association of Colleges and Employers (2013). 2013 Internship \& co-op 
survey executive summary. Retrieved August 5, 2013, from http://www.naceweb. org/uploadedFiles/Content/static-assets/ downloads/executive-summary/2013-internship-co-op-survey-executive-summary. pdf.

Parry, G., \& Warr, P. (1990). Home and employment role scale. In C. A. Beere (Ed.), Gender roles: A handbook of tests and measures (pp. 402-03). New York: Greenwood Press.

Pinder, C. C. (2008). Work motivation in organizational behavior (2nd ed.). New York: Psychology Press.

Quinn, R. P., \& Staines, G. L. (1979). The 1977 quality of employment survey. Ann Arbor, MI: Institute for Social Research.

Roznowski, J., \& Wrigley, B. J. (2003). Sign me up! Undergraduate expectations of internship programs. Journal of Advertising Education, 7(1), 21-31.

Schermelleh-Engel, K., Moosbrugger, H., \& Müller, H. (2003). Evaluating the fit of structural equation models: Tests of significance and descriptive goodness-of-fit measures. Methods of Psychological Research Online, 8(2), 23-74.

Spector, P. E. (1997). Job satisfaction: Application, assessment, cause, and consequences. Thousand Oaks, CA: Sage Publications.

Sweitzer, H. F., \& King, M. A. (2009). The successful internship: Personal, professional, and civic development (3rd ed.). Belmont, CA: Brooks/Cole.

Thiel, G. R., \& Hartley, N. T. (1997). Cooperative education: A natural synergy between business and academia. SAM Advanced Management Journal, 62(3), 19-24.

Toncar, M. F., \& Cudmore, B. V. (2000). The overseas internship experience. Journal of Marketing Education, 22(1), 54-63.

Wanous, J. P., Reichers, A. E., \& Hudy, M. J. (1997). Overall job satisfaction: How good are single-item measures? Journal of Applied Psychology, 82(2), 247-52. 